\section{Eye nutrient products for age-related macular degeneration: what do they contain?}

\author{
Abstract \\ Background and purpose Patients are \\ increasingly well informed about the \\ availability of antioxidant products and the \\ claims made for their benefits in age-related \\ macular degeneration (AMD). Consequently, \\ their use is becoming widespread. The \\ purpose of this study is to conduct a survey of \\ the commonly encountered products, and to \\ compare their ingredients with the current \\ Age-Related Eye Disease Study (AREDS) \\ recommendations.
}

Methods A search was undertaken for products sold as 'eye nutrients' at local pharmacies and health food shops, and for products advertised via the Internet.

Information about these products was collated and analysed.

Results We identified 22 eye nutrient products. Analysis of their constituents showed that, although over $75 \%$ contained all the constituents used in AREDS, only two matched the dosage profiles recommended in the study.

Conclusion The authors draw no conclusion on the efficacy of nutritional supplements in the prevention of AMD. In order to advise their patients, ophthalmologists should be familiar with these products. The compiled list in this paper should provide a useful reference for them.

Eye (2004) 18, 470-473. doi:10.1038/sj.eye.6700700

Wolverhampton and

Midlands Counties Eye Infirmary

Compton Road

Wolverhampton WV3 9QR

West Midlands, UK

Tel: + 441902645023

Fax: + 441902645018

E-mail: seema20@msn.com

Received: 5 June 2003 Accepted in revised form: 15 July 2003

Keywords: antioxidant; eye nutrient; zinc age-related macular degeneration

\section{Introduction}

In recent years, several clinical trials have been conducted to evaluate the role of zinc and antioxidant supplements for the protection
S Arora, M Musadiq, S Mukherji and YC Yang

against the development of advanced agerelated macular degeneration (AMD) and severe visual loss in elderly patients with early AMD. ${ }^{1-10}$ Current evidence for the use of such antioxidant supplements comes from the AgeRelated Eye Disease Study (AREDS), which reported that treatment with zinc and antioxidants reduced the risk of progression to advanced (AMD) and vision loss in patients who have high-risk characteristic lesions defined by extensive intermediate drusen, large drusen, noncentral geographical atrophy in one or both eyes (Category 3) or if they have advanced AMD (GA involving centre of the macula or signs of choroidal neovascularisation-Category 4) in the first eye. AREDS did not show any benefit of supplementary nutrients in patients with milder drusen and retinal pigment epithelial abnormalities. ${ }^{11}$

Although general practitioners and ophthalmologists are not routinely prescribing such supplements to patients with AMD, many patients, in our experience, are self-medicating with a variety of proprietary pharmaceutical products, which are available over the counter without prescription. In the light of recent recommendation from the AREDS on the use of high doses of vitamins and zinc and because of the scarcity of information in the medical literature on these pharmaceutical products, we conducted a survey of the commonly encountered products to investigate their constituent ingredients in relation to the current AREDS recommendations.

\section{Method}

A search was carried out in local pharmaceutical and health food outlets as well as on the Internet for products sold or advertised under the general category of 'eye 
nutrients'. For each product, information on name, manufacturer, inclusion in the British National Formulary 2002, source of purchase, recommended dosage, route of administration and dosages of constituent ingredients were collected. Inclusion in the National Health Service Drug Tariff list was also determined for each product. Where dosages were quoted in international units (IU), a conversion was made into milligrams for ease of comparison with the dosage regimen from AREDS. The conversion scale used estimated $1 \mathrm{mg}$ of vitamin $\mathrm{E}$ to be equivalent to $1 \mathrm{IU}$ of vitamin $\mathrm{E}$ and $1 \mathrm{mg}$ of Vitamin $\mathrm{A}$ to be equivalent to 833 IU of vitamin A. ${ }^{12}$

\section{Results}

In all, 22 different eye nutrient products were identified (Table 1). Nine were available from local health foods or pharmaceutical outlets and 13 others were available by purchase from Internet websites or mail order companies. These products are formulated as tablets, capsules, or in the case of PURE FOCUS ${ }^{\circledR}$, oral spray. Recommended dosages, described as 'servings per day' varies from one to six tablets or capsules per day. None of the products were specifically included in the British National Formulary, nor the National Health Service Drug tariff list indicating that these products would not be available on prescription.

Of the 22 products identified, 17 contain all the constituents used in AREDS, which are vitamin C (500 mg), vitamin E (400 IU), $\beta$-carotene ( $15 \mathrm{mg}$ ), and zinc (as zinc oxide $80 \mathrm{mg}$ ). VISIOMAX ${ }^{\circledR}$ does not contain zinc, while MACUVITE ${ }^{\circledR}$ and PURE FOCUS ${ }^{\circledR}$ does not contain any of the constituents used in the AREDS. OCUVITE PRESERVISION ${ }^{\circledR}$ and VISIVITE ORIGINAL FORMULA ${ }^{\circledR}$ were the only two products found that contain all the constituents that match the formula recommended by AREDS.

Table 1 Summary information on eye nutrient products found in this study

\begin{tabular}{|c|c|c|c|c|c|c|c|c|}
\hline Name (manufacturer) [source] & $\begin{array}{l}\text { Daily } \\
\text { dose }\end{array}$ & $\begin{array}{l}\text { Vit } C \\
(m g)\end{array}$ & $\begin{array}{l}\text { Vit A } \\
(m g)\end{array}$ & $\begin{array}{l}\text { Vit } E \\
(m g)\end{array}$ & $\begin{array}{l}\mathrm{Zn} \\
(m g)\end{array}$ & $\begin{array}{l}\mathrm{Cu} \\
(m g)\end{array}$ & $\begin{array}{l}\text { Comparison } \\
\text { to AREDS }\end{array}$ & $\begin{array}{c}\text { Other } \\
\text { constituents }\end{array}$ \\
\hline CENTRUM SILVER (Wyeth) [Internet] & $1 \mathrm{tab}$ & 60 & 4 & 45 & 15 & 2 & All doses lower & $1,3,4,8$ \\
\hline CLINICAL NUTRIENT EYE (Bnatural) [Internet] & 3 tab & 600 & 6 & 60 & 9 & 1 & $\begin{array}{l}\text { Lower vit E, A } \\
\text { and zinc }\end{array}$ & $1,3,4,5,8$ \\
\hline EYEBRIGHT (Rosemary's) [Retail] & $1 \mathrm{tab}$ & 250 & 3 & 50 & 15 & - & All doses lower & $1,5,6,8$ \\
\hline EYEBRIGHT COMPLEX (Solgar) [Retail] & 2 cap & 300 & 3 & 83 & 10 & - & All doses lower & $1,2,3,5,6,8$ \\
\hline EYE CARE FORMULA (Nutricia) [Retail] & $2 \mathrm{tab}$ & 600 & 1.86 & 134 & 15 & 3 & $\begin{array}{l}\text { Lower vit E, } \\
\text { A, zinc }\end{array}$ & $1,2,4,5,8$ \\
\hline EYE SUPPORT (Baar Product) [Internet] & 3 cap & 300 & 15 & 200 & 25 & - & $\begin{array}{l}\text { Equivalent in } \\
\text { vit A only }\end{array}$ & $1,3,4,5,8$ \\
\hline EYE VITES (Allergan)[Retail] & $1 \mathrm{tab}$ & 200 & 6 & 100 & 6 & 2 & All doses lower & 8 \\
\hline ICAPS (Alcon) [Retail] & $2 \mathrm{tab}$ & 400 & 4 & 150 & 60 & 4 & Lower vit $\mathrm{E}, \mathrm{A}$ & $1,3,4,8$ \\
\hline MACUVITE (Springfield) [Internet] & $2 \mathrm{tab}$ & - & 一 & - & - & 一 & $\begin{array}{l}\text { No AREDS } \\
\text { constituents }\end{array}$ & 1,2 \\
\hline MAXIVISION (Medical Ophthalmics)[Internet] & 4 cap & 500 & 9 & 400 & 30 & 2 & $\begin{array}{l}\text { Lower vit A } \\
\text { and zinc }\end{array}$ & $1,3,4,5,6,7,8$ \\
\hline OCUGUARD PLUS (Twinlab) [Internet] & 4 cap & 1500 & 48 & 400 & 25 & - & $\begin{array}{l}\text { Very high vit A } \\
\text { and } C \text {, lower zinc }\end{array}$ & $1,3,4,5,6,7,8$ \\
\hline OCUPOWER (Neutraceutical) [Internet] & 6 cap & 1500 & 18 & 500 & 25 & 1 & $\begin{array}{l}\text { Very high vit } C \text {, } \\
\text { lower zinc }\end{array}$ & $1,3,4,5,6,7,8$ \\
\hline OCUVITE (Bausch and Lomb) [Pharmacy] & $1 \mathrm{tab}$ & 200 & 1.2 & 60 & 40 & 2 & All doses lower & 1 \\
\hline OCUVITE- PRESERVISION (Bausch and Lomb) [Pharmacy] & $2 \mathrm{tab}$ & 452 & 15 & 400 & 69.6 & 1.6 & Equivalent in all & \\
\hline OCUVITE LUTEIN (Bausch and Lomb) [Internet] & 1 cap & 60 & - & 30 & 15 & 2 & $\begin{array}{l}\text { All doses lower } \\
\text { no vit A }\end{array}$ & 1 \\
\hline OCUVITE XTRA (Bausch and Lomb) [Internet] & $1 \mathrm{tab}$ & 300 & 1.2 & 100 & 40 & 2 & All doses lower & $1,3,4,7,8$ \\
\hline OPTIMEYES (Bodywise) [Internet] & 3 tab & 1000 & 9 & 100 & 20 & 2 & Very high vit $\mathrm{C}$ & $1,3,5,6,8$ \\
\hline PURE FOCUS (Vision Works) [Internet] & 3 puff & - & - & - & - & - & $\begin{array}{l}\text { No AREDS } \\
\text { constituents }\end{array}$ & $1,2,8$ \\
\hline VISIOMAX (Wassen) [Retail] & $1 \mathrm{tab}$ & 90 & 2.5 & 12 & - & - & $\begin{array}{l}\text { Lower than } \\
\text { AREDS, no zinc }\end{array}$ & $3,4,5$ \\
\hline VISIONACE (Vitabiotics) [Retail] & 1 tab & 150 & 0.3 & 60 & 7.5 & 1 & All doses lower & $3,4,5,8$ \\
\hline VISI VITE ORIGINAL FORMULA (Vitamin Science) [Internet] & 2 cap & 500 & 15 & 400 & 80 & 2 & Equivalent in all & \\
\hline VISI VITE SMOKER'S FORMULA (Vitamin Science) [Internet] & 2 cap & 500 & - & 400 & 80 & 2 & $\begin{array}{l}\text { Equivalent } \\
\text { without Vit A }\end{array}$ & 1 \\
\hline
\end{tabular}

Code for other constituents: $1=$ lutein, $2=$ zeaxanthin, $3=$ selenium, $4=$ vitamin $B$ complexes, $5=$ bilberry, $6=$ taurine, $7=$ glutathione, $8=$ others 


\section{Vitamin C}

Maxivision, Visivite Original Formula and Visivite Smoker's Formula have an exact dose match for vitamin $C$ with AREDS recommended dose of $500 \mathrm{mg} /$ day. This is equivalent to $625 \%$ of recommended daily allowance (RDA). ICAPS, Eye Care Formula, Clinical Nutrient Eye and Ocuvite Preservision contain Vitamin C dosages very close to the recommended dosage while others were less comparable. For instance, Ocuguard Plus and Ocupower contain three times the recommended dosage. A few products have vitamin $\mathrm{C}$ contents lower than the AREDS recommended dosage.

\section{及-Carotene (Vitamin A)}

Eye Support, Ocuvite-Preservision and Visivite Original Formula contain the same vitamin A content as the AREDS recommended dose ( $15 \mathrm{mg})$, which is equivalent to $1875 \%$ of RDA. Ocuguard Plus and Ocupower were the only products found with vitamin A content higher than the AREDS recommendation.

\section{Vitamin E}

The dosage of Vitamin E used in AREDS was $400 \mathrm{mg}$. This is equivalent to $2666 \%$ of the RDA. We found that Maxivision, Ocuguard Plus, Ocuvite Preservision, Visivite Original Formula and Visivite Smoker's Formula contained $400 \mathrm{mg}$ of vitamin E, while many other products had much lower vitamin E content.

\section{Zinc}

Ocuvite Preservision, Visivite Original and Visivite Smoker' Formula contain an equivalent amount of zinc as that recommended by the AREDS $(80 \mathrm{mg})$. This represents $842 \%$ of RDA. However, all the other products contain less than this amount with some containing as low as $6 \mathrm{mg}$.

\section{Copper}

The formulations used in AREDS contained copper supplements in the form of $2 \mathrm{mg}$ cupric oxide to prevent copper deficiency anaemia, which can occur from high doses of zinc. Nine of the products contained at least $2 \mathrm{mg}$ of copper and one product contain $4 \mathrm{mg}$. Eyebright, Eyebright complex, Eye support, and Ocuguard plus contain zinc but no copper.

\section{Other ingredients}

Pure Focus is the only product with a single ingredient of lutein. Many other products contain numerous other ingredients, such as lutein, selenium, zeaxanthin, vitamin
B complex, bilberry, and other herbal extracts, iodine, manganese, and magnesium. Ocupower contains as many as 36 ingredients.

\section{Discussion}

We found a wide array of eye nutrient products available for patients to purchase over the counter, via the Internet or mail order without a prescription. It was not possible to include all the products identified in our search, as they were too numerous. We believe the list we have compiled in this report is fairly comprehensive and is likely to be a useful source of reference for medical practitioners and ophthalmologists who may have to advise their patients on such medications.

Although it is generally acknowledged that zinc and antioxidant supplementation in patients with moderate to severe ARMD has been shown to delay progression of macular disease and visual decline, there has not been any firm guidance on the routine prescription of these products for potentially suitable patients. ${ }^{10}$ Several of the eye nutrient products we surveyed, for example, OCUVITE were listed on the Part XVIIIA list ('black list') of the National Health Service Drug tariff for England and Wales and therefore cannot be prescribed normally. As none of these products are actually licensed, the Prescription Pricing Authorities of Primary Care Trusts in England and Wales would generally not approve of the prescription charges. Therefore, when patients wish to consider paying for their eye nutrient products and seek our advice regarding the decision to use such products, it is important to ensure that they understand the evidence available on the benefit of such products. It is important that patients understand the different types of ARMD as this helps them to understand the evidence that supplements are beneficial only if they have high-risk characteristics in one or both eyes or if they have advanced ARMD in the fellow eye. There is currently still no evidence that supplement help to reduce the risk in patients with mild disease. It is also important that they appreciate the variation between different products and their potential adverse effects.

In AREDS, the dosages of the antioxidants are much higher than the recommended daily allowances. The daily recommended dietary allowances (RDA) for vitamin C is $75-90 \mathrm{mg}$, vitamin E $15 \mathrm{mg}$, vitamin A 700-900 $\mu$ g, zinc 8-11 mg, and copper $900 \mu \mathrm{g} .{ }^{13,14}$ Comparing AREDS dosages to normal daily recommended allowances; vitamin $\mathrm{C}$ is six times more, vitamin $\mathrm{E}$ is 26 times more, vitamin $\mathrm{A}$ is 18 times more and zinc is eight times more. Patients must realise that it would be difficult in a normal diet to achieve the high doses used in AREDS and for them to achieve the amount of risk reduction seen in the AREDS population, 
it is probably necessary to supplement their normal intake of zinc and antioxidants.

The variation in dosages of the main constituents of the eye nutrient products could also present a potential quandary for patients. Vitamin $C$ varied from 0 to $1500 \mathrm{mg}$ in the group of products surveyed in this study, while vitamin E varied from 0 to $500 \mathrm{mg}$, vitamin A from 0 to $48 \mathrm{mg}$, and zinc from 0 to $80 \mathrm{mg}$. As AREDS ${ }^{11}$ is the only study to have shown a treatment benefit, it is not known whether higher or lower dosages of constituents than those used in the AREDS would have any different effect. Furthermore, the variation in dosages of the constituents may not have actually result in as much variation in the effective dose due to differences in the shelf-life of the products to account for natural degradation of the constituents.

Although adverse effects of high-dose antioxidants and zinc are infrequent, it is worth noting that copper deficiency anaemia from zinc and risk of lung cancer are potential risks. It was surprising to find that some products like Eyebright, Eyebright complex, Eye support, and Ocuguard Plus contain zinc but no copper.

The risk of lung cancer in smokers attributable to $\beta$-carotene means that some eye nutrient products might be contraindicated in smokers. For smokers or recent smokers (within 5 years), VISIVITE smokers formula, which has vitamin A replaced by another carotenoid, lutein, may be a safer choice.

At present, the routine use of eye nutrient products by patients at risk of visual loss to AMD is still controversial despite the positive results from AREDS. Although results from other large-scaled studies may also support their role in the future, it is likely that the issue will remain controversial. Owing to the devastating effects of AMD on visual function, patients will continue to seek all possible means of prophylaxis. In the absence of firm guidelines on prescribing policy of such products, it is important for clinicians to be equipped with some basic and essential knowledge on eye nutrient products in order to assess and counsel patients properly.

\section{References}

1 West S, Vitale S, Hallfrisch J, Munoz B, Muller D, Bressler S et al. Are antioxidants or supplements protective for age related macular degeneration? Arch Ophthalmol 1994; 112: 222-227.

2 Newsome DA, Swarz M, Leone NC, Elston RC, Miller E. Oral zinc in macular degeneration. Arch Ophthalmol 1988; 106: $192-198$.

3 Holz FG, Wolfensberger TJ, Piguet B, Gross-Jendroska M, Arden GB et al. Oral zinc-therapy in age-related macular degeneration: a double-blind study (abstract). German J Ophthal 1993; 2: 391.

4 Kaiser HJ, Flammer J, Stumpfig D, Hendrickson P. Visaline in the treatment of age related macular degeneration: a pilot study. Ophthalmologica 1995; 209: 302-305.

5 Stur M, Tittl M, Reitner A, Meisinger V. Oral zinc and the second eye in age related macular degeneration. Invest Ophthalmol Vis Sci 1996; 37: 1225-1235.

6 Richer S. Multicenter ophthalmic and nutritional age related macular degeneration study-Part 2: antioxidant intervention and conclusions. J Am Optometry Assoc 1996; 67: 30-49.

7 Taylor HR, Tikellis G, Robman LD, McCarty CA, McNeil JJ. Vitamin E supplementation and age-related maculopathy (abstract). Invest Ophthalmol Vis Sci 2001; 42: S311.

8 Taylor HR, Tikellis G, Robman LD, McCarty CA, McNeil JJ. Vitamin E supplementation and macular degeneration: randomised controlled trial. BMJ 2002; 325(7354): 11.

9 Smith W, Mitchell P, Webb K, Leeder SR. Dietary antioxidants and age-related maculopathy: the Blue Mountains Eye Study. Ophthalmology 1999; 106: 761-767.

10 Evans JR. Antioxidant vitamin and mineral supplements for age-related macular degeneration. Cochrane Database Syst Rev 2002(2): CD000254.

11 Age Related Eye Disease Study Group. A randomised, placebo-controlled, clinical trial of high-dose supplementation with vitamin $\mathrm{C}$ and $\mathrm{E}$, beta carotene, and zinc for age related macular degeneration and vision loss: AREDS report no. 8. Arch Ophthal 2001; 119: 1417-1436.

12 Bayer consumer care division. One a Day 2001. http:/ / www.bayercare.com/oad/faqgen.html. (accessed 26th February 2003).

13 Garrow JS, James WPT Human Nutrition and Dietetics, 9th ed. Churchill Livingstone: UK 1998.

14 National Academy of Science, Food and Nutrition Board. Dietary Reference Intakes Tables 2003. http://www.iom.edu/ IOM/IOMHome.nsf/Pages/Food + and + Nutrition + Board. (accessed 25 April 2003). 